\title{
THE PROCESS OF CHILDREN'S ABILITY TO ASK QUESTIONS FROM AN INTERACTIVE PERSPECTIVE
}

\author{
Maria Rosa Solé Planas
}

\section{Introduction}

Children begin to ask questions at around two years of age and develop the skill throughout early childhood. This laborious and complex ability is due to changes that take place on an individual level in the cognitive, linguistic and pragmatic domains, and also to interpersonal factors - the influence of adult interlocutors in this process.

Interrogative utterances frequently appear in the linguisic repertoire of adults who interact with very young children. Various authors who have studied dialogue between adults and children have noted this and have debated the function of questions within this dialogue.

Savonic (1975) observed that adults more frequently use questions than declarative or interrogative productions in these interactions, and that this tendency reverses when children begin to form questions. Garvey (1975) considers that adults use questions that perform the function of indirect requests for action (e.g., will you give me the ball?) rather than imperative forms such as "give me the ball" to control children's behavior.

For Olsen-Fulero (1983) questions are among the most frequent means used in conversation to pass the turn. This author considers that for adults interacting with young children the aim of questions is to elicit a verbal intervention from their interlocutors, and that three-year old children are more likely to accept their turn to speak after a question than after a declarative utterance. Adults are fully conscious of the limitations of the communicative skills of the children and use questions to keep the conversation going. Snow (1986) stresses the facilitating nature of questions in general, and lays special emphasis on the role of clarifying questions in bringing children into the conversation:

"Seeing children as relatively incompetent conversational partners helps us to understand why language addressed to children is so full of questions (attempts to pass the turn to the child), clarifying questions and expansions (attempts to clarify and upgrade child turns)."

As can be seen, these studies all note that questions appear very frequently in the speech of adults who interact with children under the age of three. The functions attributed to adults' questions are, on the one hand, encouraging the verbal intervention of children in the conversation, and, on the other, making possible an indirect form of control of the children's behavior. 


\section{The study of the development of children's questions}

The studies of Malrieu and Laurentis (1966) and Tran-Thong et al (1978) indicate that children's first questions appear during the second year of life, due to factors related to the activity in which they are engaged, and to interpersonal factors related to the role of their adult interlocutors. These utterances contain a single element, produced with a rising tone. Between the ages of 18 and 20 months children can perform a series of manipulations of objects around them: They put one object on top of another, and put things together and take them apart. They are not yet able to perform activities such as putting a jigsaw together or building a tower with blocks. When children are faced with a problem that they cannot solve they ask adults for the information that they need; this information is asked for in question form. The children's aim is to obtain information about objects in their immediate vicinity, and then to act on the basis of the information given. For this reason, the first questions that children produce refer to objects that are present, or to actions related to the ongoing activity. From the third year onwards, as they develop intellectually, children begin to form questions about absent objects or people, or about events with no immediate connection with the present. They ask about a missing object, or who has caused a certain thing to happen. In this way, another basic function emerges: Asking questions to acquire information.

A more recent study (Vaidyanathan 1988) stresses the plurifunctional nature of questions. This study defines two broad groups of questions formed by children. The first group includes questions which aim to obtain information, and the second includes questions given the generic term "non-informative", covering a wide range of functions: Calling the attention of the interlocutor, confirming or clarifying information, obtaining permission, starting a conversation, affirming, proposing or suggesting an action, and prohibiting. With this classification the range of possibilities that questions offer expands substantially; it considers aspects which go beyond the simple task of requesting information.

\section{Objectives of the study}

In the first phase of our project we aim to present a descriptive study of the questions that appear in the linguistic production of children aged between 2 and 3 , and of the evolution that these questions undergo during this period. We use the term "descriptive" because our objective is to study the content and formal aspects of questions so as to establish a typology of questions and thus to determine the function or functions that questions perform in children's speech.

We will first clarify the type of utterance that we include in the category "question". Since the samples of speech that we analyze come from dialogues between adults and children we consider that a question inside a conversation is defined as the production by the speaker of an utterance which aims to elicit a response from the interlocutor. As far as form is concerned, the interrogative utterance in Catalan and in Spanish has one of the following features:

a) it retains the word order of the declarative sentence: Verb and subject are not inverted, as is the case with other languages. The only difference lies in the rising tone in which the question is expressed. In the two utterances "ha llegado 
papa" (Daddy has arrived) and "iha llegado papạ?" (has Daddy arrived?) it is only this rise in intonation that distinguishes between them.

b) the utterance is headed by an interrogative particle such as ique?, (what?) ¿quién? (who?) ¿donde? (where?) ¿por qué? (why?), e.g. ¿Qué hace la niña? (What is the girl doing?), ¿Qué es esto? (What's this?), Dónde está el coche? (Where's the car?) etc.

c) the production of the interrogative monosyllables isi?, ino? in response to a declarative sentence produced by the interlocutor, e.g., Adult: Papa se ha ido de viaje. Child: ¿St? (Adult: Daddy's gone on a journey. Child: Yes? - or the total or partial repetition of the utterance produced by the interlocutor, e.g. Adult: Esto es una raqueta. Child: ¿Raqueta? (Adult: This is a racket. Child: Racket?)

\section{Methodology}

\section{Population}

Questions made by four children - one girl and three boys between two and three years old - were analyzed. They came from middle-class urban families with a high socio-cultural level. Two children, the girl and one of the boys, were monolingual (Catalan) and the others were bilingual in Catalan and Spanish. One was a family bilingual and the other an environmental bilingual - the language used in his family is Catalan, but most other people with whom he comes into contact speak Spanish. The use of monolinguals and bilinguals in this project is perfectly valid since the study stresses the content and function of questions rather than their grammatical or syntactical features. In addition, the syntactical structure of questions is similar in Catalan and Spanish. As mentioned above, unlike other languages, Catalan and Spanish do not use the inversion of subject and verb, or an auxiliary verb such as "do" in English. Word order is the same as in declarative utterances, or, alternatively, an interrogative particle is used. Both languages can omit the subject pronoun, as the subject is made explicit by the inflection of the verb.

\section{Procedure}

The questions analyzed form part of wider longitudinal study. The material used here consists of monthly 45 -minute video recordings of the children in their homes. Natural settings, in which the child and the adult in question are involved in a common activity - such as bath time, mealtimes, and playtime - were selected.

\section{Categories of questions analyzed}

On the basis of the form and content of the children's questions, the following categories were established: Referential questions, regulative questions, instrumental questions, and socio-communicative questions.

The aim of referential questions is to acquire information concerning the physical surroundings (present or absent objects or toys) or the social environment 
(questions about the activity, state, intentions or experiences of the people in the child's environment, such as ¿qué haces?, what are you doing?, or ite gusta el coche? do you like the car?); alternatively, the information requested may deal with more general events.

Children's questions about objects around them refer basically to the identity of the object. The category includes questions about the name of the object (the reference iqué es?, what is it?). Another group of questions center on the location of an object or person (idonde?, where?); the actions of objects or people (ique hace la pelota?, what is the ball doing?) the properties of objects (ide que color es la pelota?, what color is the ball?) or possession (ide quien es?, whose is it?).

The category referential questions include open questions that request precise information from the interlocutor (¿qué es esto?, what is this?, ¿qué quieres?, what do you want?) and closed questions which only require an affirmative or negative answer (iquieres chocolate?, do you want some chocolate?, ite duele la rodilla?, does your knee hurt?), known as "yes/no" questions. Open questions always contain an interrogative pronoun such as ¿qué?, what?, ¿quién?, who?, ¿donde?, where?), and closed questions are utterances constructed in the same way as declarative sentences, but with a rise in intonation at the end. The basic function of referential questions is to obtain information, to find out something new about an object or person. The acquisition of this information, however, is not followed by immediate action.

Regulative questions include a range of questions with a common aim, i.e. that the interlocutor should perform a particular action or give a certain piece of information. This action or information has a favorable effect on the activity that the questioner is involved in or is proposing. In both cases the purpose of the question is that someone - the child or the interlocutor - should act. The form of regulative questions is the same as that of declarative utterances, except that they end with a rising intonation (e.g. ime abres la puerta?, literally "you open the door for me?"). Within this group a distinction is made between requests for action, requests for guidance and requests for permission to perform an action.

In a request for action, the child asks the adult to perform a specific activity (e.g. ime ayudas?, will you help me?, literally "you help me?"). Requests for guidance are questions that the child puts to the adult before carrying out a specific activity (e.g. ¿aqui?, here? if he/she is doing a jigsaw and does not know where to put a particular piece). Requests for permission to perform an action are questions in which a child asks for the approval of an adult before performing an action (e.g. iabro?, I open?, asked a child with a box of crayons in his/her hand.

Instrumental questions are those in which the subject asks the interlocutor for a particular object. They are indirect requests for an object (ime das la raqueta?, will you give me the racket?).

Socio-communicative questions include requests for clarification, confirmation or repetition of the utterance of the previous speaker. These questions do not contribute new information to the subject of the conversation (Corsaro 1977). Socio-communicative questions arise in the course of the communication between the child and the adult and often express the doubt or surprise produced by the fact that the speaker has not understood what the other person has just said. The aim of socio-communicative questions is to maintain the flow of the conversation and repair the breakdowns that occur. 


\section{Results}

The children in our study used referential questions most frequently, followed by regulative and socio-communicative questions and then by instrumental questions (see figure 1).

In the analysis of referential questions two variables were taken into account - the content of the questions and the age of the subjects. The content of the questions was divided into three blocks - objects, people and events. Two age blocks were defined, from $2-2.5$ years and from $2.5-3$, in order to determine whether there were modifications in the type of questions asked during the period (see figure 2).

The analysis of content of questions about objects (figure 3 ) shows that the highest proportion of questions concerned the identity and the relation of the object. Questions concerning the identity of the object included iqué es?, what is it?, ¿qué es esto?, what is this?, ¿quién es?, who is it?, questions which aim to discover the name of an object, person or animal as mentioned above. The "relation" category included questions concerning the location or an object or person (e.g. ¿dónde está el coche?, where is the car?, ¿dónde está papá?, where is Daddy?, or simply ¿dónde?, where?, when the child was looking for a toy and could not find it), and questions about the possession of an object, e.g. ¿de quién es la pelota?, whose is the ball?. Questions involving the action of a moving object or person, e.g. ¿qué hace?, what is she/he/it doing? were less frequent, and the least frequent of all were questions concerning the properties of objects and animals; in this case most questions concerned color.

As for age, the second variable, in both age groups questions about objects were the most frequent.

Figure 2 shows that the questions that children ask to acquire information about the adult interlocutor or about matters or events of a more general nature increased markedly from 2.5 to 3 years. Children show more interest in their interlocutor as they grow older. The state, experience or intentions of the interlocutor stimulate the production of these questions; one child touched his minder's cheek, and asked itata pupa?, (have you hurt yourself?)

The questions about events refer to more general aspects of the surroundings. Children try to find explanations for a particular phenomenon that they observe, e.g. ¿por qué pica el jabón?, why does soap sting?, asked a child in the bath; ipapa se va?, is Daddy going?, asked a child on seeing that his father was leaving the room. The children also showed interest in words that they heard and that were new to them: ¿qué es la música?, what is music? or ¿qué es un problema?, what is a problem?, asked a child after hearing his mother use the words. At around the age of three, children are observed to show a growing interest in the meaning of words. This attitude reveals a change in their cognitive capabilities. Children's questions diversify in terms of content and pass from being simple requests for the name of an object to being questions about the meaning of specific words.

Among regulative questions (see figure 4) requests for guidance were by far the most frequent. Children involved in an activity turned repeatedly to adults when they did not know how to proceed. Requests for action, either involving the adult 
directly, such as iabres?, open (the door)? asked by a child to his mother, or those proposing a joint activity between adult and child, e.g. ipintamos?, shall we paint?, ¿jugamos con el tren?, shall we play with the train?, again child to mother, came second. Requests for permission to perform an action were a distant third.

Among socio-communicative questions, clarifying questions were the most frequent (see figure 5). In these questions, as mentioned above, children repeat totally or in part the utterance produced immediately before by their adult interlocutor. Requests for clarification show that the child does not know certain words or expressions used by the adult. They constitute a device that the child uses to obtain further information about what has just been said. Some examples:

1. Adult (A) (holding a toy in her arms): El Snoopy está con la raqueta, (Snoopy's got a racket).

Child (C): iraqueta? (racket?)

2. An adult and child looking at a picture book:

A: $\quad$ iMira, aquí van de paseo! (Look, they [some bears] are going for a walk!)

C: iPateo? (Walk?) (mispronounced)

3. A: Es la cunita donde hace nonon (It's the cot where [the bear] goes bye-byes)

C: iNonos? (Bye-byes?)

A: Sí, como tú. (Yes, like you).

Confirmation questions appear less frequently than requests for clarification. As mentioned above, these questions show the speaker's surprise or disbelief at the information he/she has just received. They are the monosyllables ist? and ino? which the child uses in response to an utterance by an adult. Two examples:

4. A: Papá no vendrá a cenar. Daddy isn't coming for supper.

C: $\quad$ iNo? (No?)

5. A: Ha venido el señor del super. The man from the supermarket has come.

C: iSi? (Yes?)

\section{Discussion}

The content of questions changes with the age of the subjects. Between the ages of two and two and a half, questions about objects predominate; between two and a half and three, these questions are still the most frequent, although there is a notable increase in questions about people, and especially about their activities, experiences and states. This appears to indicate that initially children are interested in physical entities (objects, people and animals) and in identifying and naming them. During the first phase the priority is to discover the names of objects and the interest in information about the activities of animals and people is only minor. Another topic which arouses a considerable number of questions is the location of objects. Children are used to objects being in certain specific places and are surprised if they are not there. When they do not find a particular object, they ask 
the question idonde esta? (where is it?). In contrast, children appear less interested in the properties of objects around them, such as color, shape or size.

One plausible explanation for the formulation of the type of referential questions analyzed here lies in the stage of psychological development of these children, and the level of their knowledge of reality. In a number of works Piaget propounded that language is a logical consequence of the prior development of certain cognitive structures. Bloom, in studies of children's first productions (1973, 1975 ) noted that children learn precisely those words and structures that codify the conceptual notions of the world of objects, events and relations. According to Bloom, during the sensorimotor period children learn that things exist, stop existing and then return. They also realize that people do things with objects and that objects can be possessed and located in space. It therefore seems reasonable to expect that during the third year of life children's referential questions will address these subjects which are the continuation of the knowledge constructed during the sensorimotor period - where an object is, what it does, what it is called, and who it belongs to.

Regulative questions aim to influence the behavior of the interlocutor, requesting help, guidance or permission to perform an action. They express an indirect request for action and their aim is to make the adult act or facilitate the action of the child, on the basis of the information that the adult provides. This type of question demonstrates again the importance of action in the initial phases of development. At the ages studied here, most of the activities that the children perform center on action and the manipulation of objects. However, the children present limitations due to their inexperience and age. This inexperience brings with it an inability to surmount certain problems; for this reason children ask the interacting adult for help with the most immediate difficulties. The presence of regulative questions and especially indirect requests for action and requests for guidance confirm the results of previous studies which note that what drives children to ask questions in the first stages of development is the need to act (Laurentis and Malrieu 1966; Tran-Thong et al 1978).

Socio-communicative questions differ from those that we have just examined since they arise in response to the course that the conversation takes. The origin of these questions is to be found then in the linguistic utterances of the speaker. These utterances cause surprise in the child because of the information that they contain, or incomprehension because of the choice of vocabulary, or, alternatively, may simply be inaudible. In all these cases the function of socio-communicative questions is to reestablish the communicative situation by clarification, repetition or confirmation of the utterance or word produced by the adult.

\section{Conclusions}

Questions form a part of the linguistic repertoire of children from a very early age. They reflect children's cognitive and social development and have a markedly interpersonal nature, since the questions are addressed to the adult interlocutor. Questions perform a wide range of roles in the speech of children aged between two and three. They serve to obtain information about the surroundings (referential questions), act as indirect requests for action (regulative questions) and as indirect 
requests for objects (instrumental questions) and ask for clarification or confirmation of an ambiguous or unclear message in the interests of the continuation of the dialogue (socio-communicative questions).

\section{KINDS OF QUESTION ASKED BY CHILDREN}

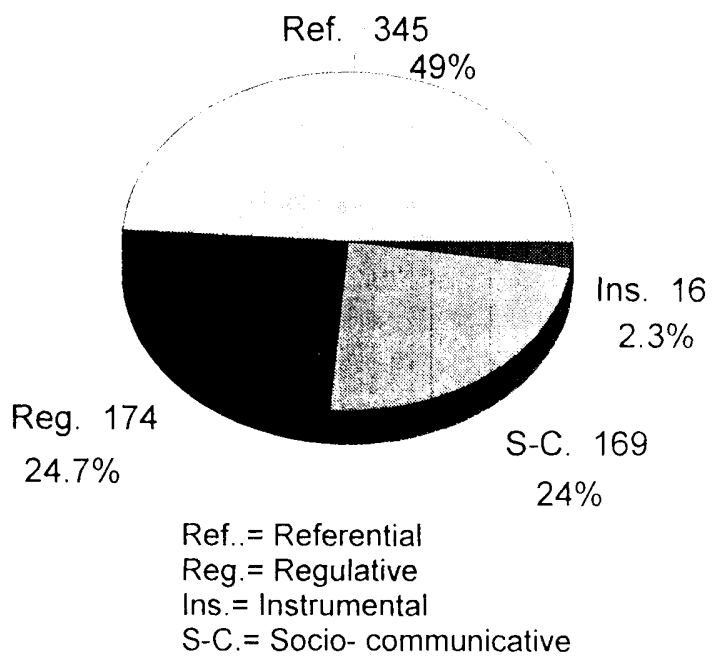

Figure 1. $\mathrm{S}-\mathrm{C} .=$ Socio- communicative 


\section{Referential Questions}

related to age

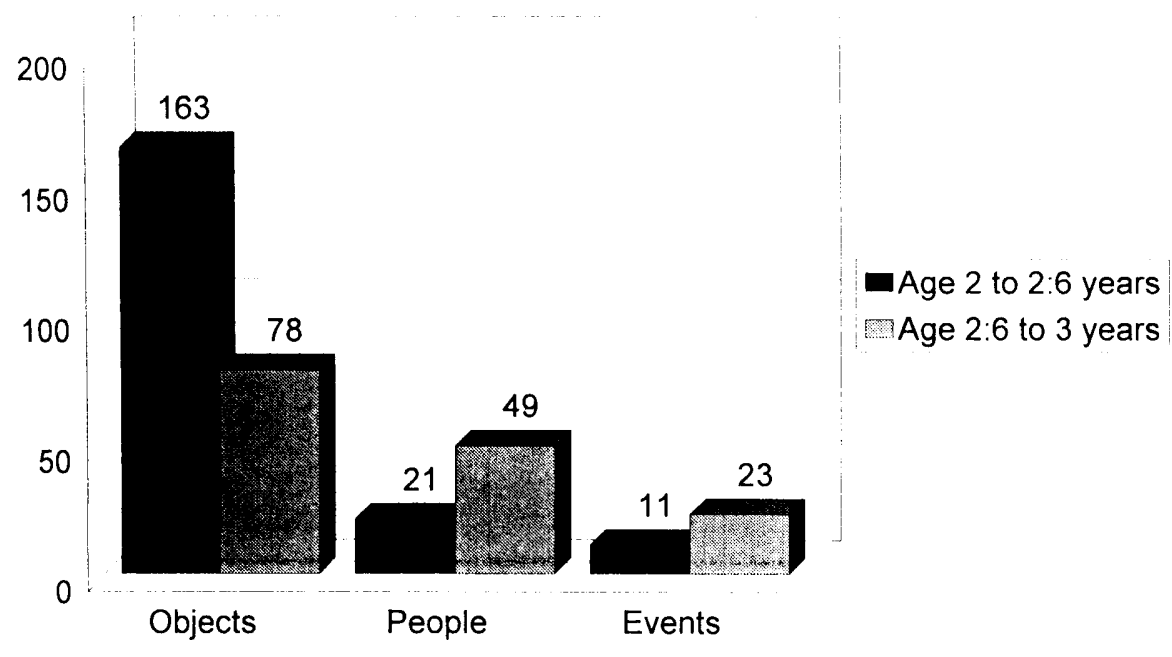

Figure 2

\section{Referential questions: Objects}

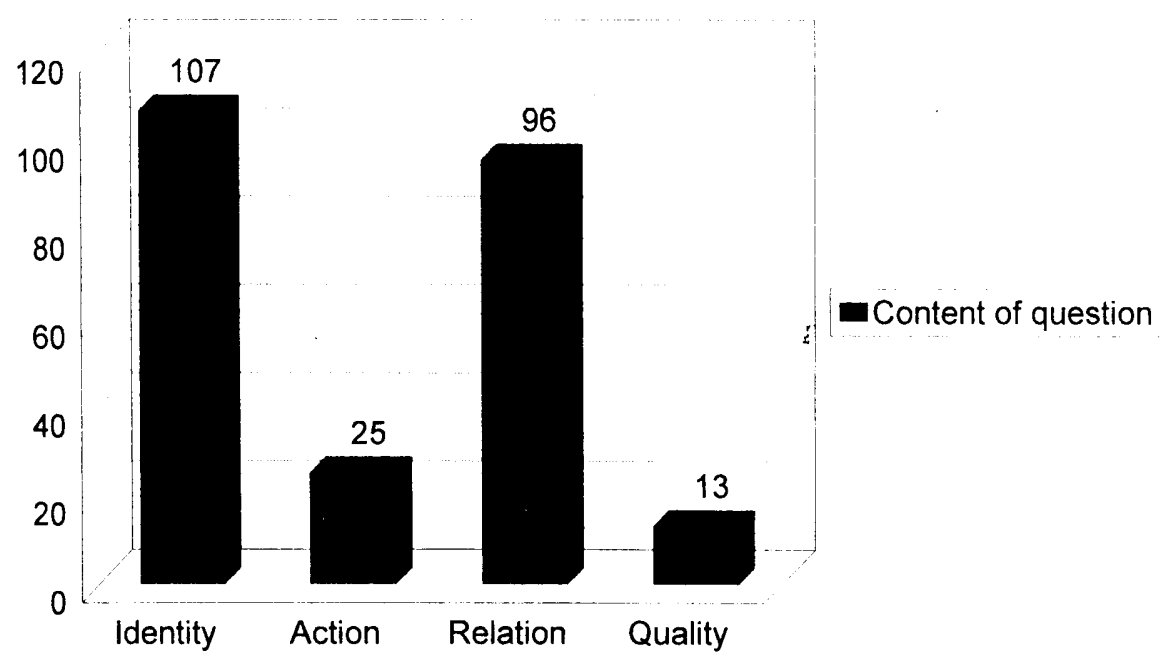

Figure 3 


\section{Regulative questions}

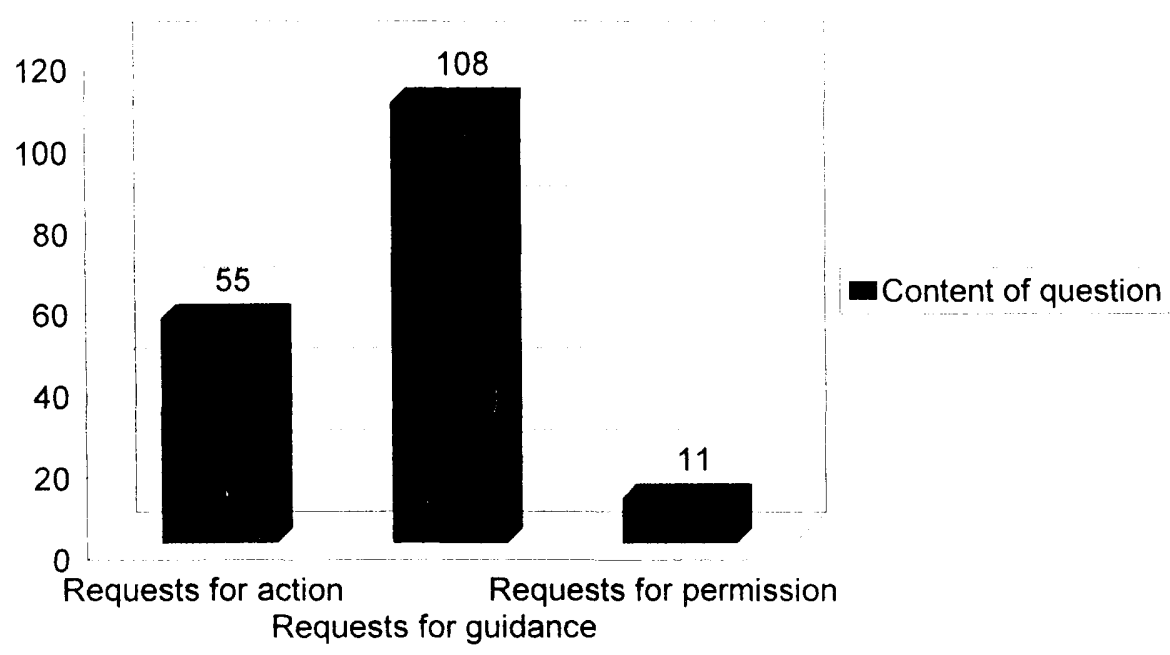

Figure 4

\section{Socio-communicative questions}

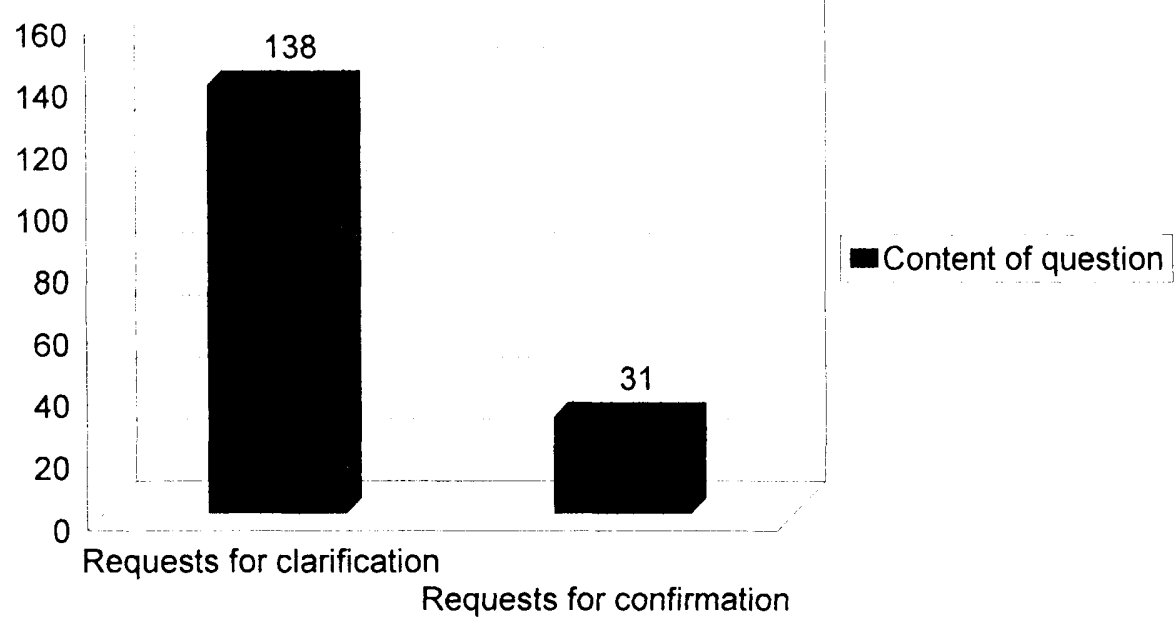




\section{References}

Bloom, L. (1970) Language development: Form and function in emerging grammars. Cambridge, Mass: MIT Press.

Bloom, L. (1973) One word at a time: The use of single-word utterances before syntax. The Hague: Mouton.

Brown, R. (1968) "Developmental of wh-questions in child speech." Journal of Verbal Learning and Verbal Behavior 7.279-90.

Cairns, H.S. \& J.R. Hsu (1978) "Who, why, when and how: A developmental study." Journal of Child Language 5.477-48.

Corsaro, W.A. (1977) "The clarification requests as a feature of adult interactive styles with young children." Language in Society 6.183-207.

Erreich, A. (1984) "Learning how to ask: Patterns of inversion in yes-no and wh-questions." Journal of Child Language 579-592.

Ervin-Tripp, S. \& D. Gordon (1980) "The development of requests." In R. Schiefelbusch (ed.), Language competence: Assesement and intervention. New York: College-Hill Press.

Folger, J.P. \& R.S. Chapman (1978) "A pragmatic analysis of spontaneous imitations." Journal of Child Language 5.25-38.

Gallagher, T. (1981) "Contingent query sequences within adult-child discourse." Journal of Child Language 8.51-62.

Garvey, C. (1975) "Requests and responses in children's speech" Journal of Child Language 2.41-63.

Hekken, Suus van, M. Dent \& H. Cathy (1982) "More questions than answers: A study of questionanswer sequences in a naturalistic setting." Journal of Child Language 9.445-460.

Holzman, M. (1972) "The use of interrogative forms in the verbal interaction of three mothers and their children." Journal of Psycholinguistics Research 1.311-37.

Hood, L. \& L. Bloom (1979) "What, when and how about why: A longitudinal study of early expressions of causality." Monographs Soc.Res.Ch.Devel 181.1-40.

Johnson, E.E. (1980) "Contingent queries: The first chapter." In H. Giles, W. Robinson \& P. Smith (eds.), Language: Social psychological perspectives. Oxford: Pergamon Press.

James, S.I. \& M.A. Seaback (1982) "The pragmatic function of children's questions. Journal of Speech and Hearing Research 5.2-12.

Kearsley, G.P. (1976) "Questions and question asking in verbal discourse: A cross-disciplinary review." Journal of Psycholinguistics Res 5.355-375.

Malrieu, Ph. \& M. Laurenties (1966) "Questions et pensée chez le jeune enfant." Bulletin de Psychologie 457-474.

Meyer, W.J. \& J. Shane (1973) "The form and function of children's questions." Journal of Genetic Psychology 123.285-296. 
Mischler, E.H. (1975) "Studies in dialogue and discourse. II. Types of discourse initiated by and sustained through questioning." Journal of Psycholinguics Res 4.99-121.

Olsen-Fulero, L. \& J. Conforti (1983) "Child responsiveness to mother questions of varying type and presentation." Journal of Child Language 10.495-520.

Piaget, J. (1968) La formation du symbole chez l'enfant. Neuchâtel: Délachaux et Niestlé.

Przetacznik-Gierowska, M. \& M. Ligeza (1990) "Cognitive and interpersonal functions of children's questions." In G. Conti-Ramsden \& C.E. Snow (eds.), Children's language 7.69-101. Hillsdale: Erlbaum Associates.

Savic, S. (1975) "Aspects of adult-child communication: The problem of question acquisition." Journal of Child Language 2.231-260.

Savic, S. (1978) "Algunas funciones de las preguntas hechas por los adultos a los niños pequeños." In Pablo del Rio (ed.), Symposium de la Asociación de Psicología Científica Francesa La génesis del lenguaje. Madrid, 173-182.

Shatz, M. (1979) "How to do things by asking: Form-function pairings in mothers questions and their relations to children's responses." Child Development 4.201-213

Snow, C.(1972) "Mothers’speech to children learning." Child Development 43.549-565.

Snow, C. (1986) "Conversations with children." In P. Fletcher \& M. Garman (eds.), Language acquisition 69-89.

Tyack, D. \& D. Ingram "Children's production and the comprehension of questions." Journal of Child Language 4.211-224.

Trang-Thong, K. Barbot \& M. Bridier "La actitud interrogadora en el niño." Infancia y Aprendizaje 69-81.

Vaidyanathan, R. (1988) "Development of forms and functions of interrogatives in children: A longitudinal study in Tamil." Journal of Child language 15:3.533-549. 